\title{
Optimization of Yield and Chemical Properties of Agar Extracted from Melanothamnus Somalensis from Oman
}

\section{Sea}

\author{
Zainab Mohammed Al-Nahdi ${ }^{1}$, Ahmed Al-Alawi ${ }^{1}$, Insaaf Al-Marhobi ${ }^{1}$ and Ali Al-Zefiti ${ }^{2}$ \\ 1. Department of Food Science and Nutrition, College of Agricultural and Marine Sciences, Sultan Qaboos University, Al-khoud 123, \\ Oman \\ 2. Language Centre, Sultan Qaboos University, Al-khoud 123, Oman
}

\begin{abstract}
The red seaweed Melanothamnus somalensis was investigated as potential economic source of agar. The effect of different conditions of alkali pre-treatment on chemical properties of agar was evaluated. Agar was extracted by various concentrations of $\mathrm{NaOH}(4 \%, 6 \%$ and $8 \%)$ and heated at different temperatures $\left(70{ }^{\circ} \mathrm{C}, 75^{\circ} \mathrm{C}\right.$ and $\left.80{ }^{\circ} \mathrm{C}\right)$ for different durations $(2 \mathrm{~h}, 2.75 \mathrm{~h}$ and $3.5 \mathrm{~h})$. The yields - molecular weight $\left(\mathrm{M}_{\mathrm{W}}\right)$ and sulfate contents of extracted agar were analysed and characterized by FTIR spectroscopy. The yield was significantly increased at these treatments from $23.29 \%$ to $30.86 \%$. $\mathrm{M}_{\mathrm{W}}$ studied by HPLC ranged from $(12.45 \pm 0.21)$ $\times 10^{5}$ to $(8.60 \pm 2.40) \times 10^{5} \mathrm{Da}$. FTIR bands show sulfate groups in C4 and C6 of galactose and no sulfate group were found on both $\mathrm{C} 2$ of galactose and $\mathrm{C} 2$ of 3,6-anhydrogalactose. All treatments showed a high sulfate content that ranged from 5.4\% to $10.1 \%$. These properties were found to be significantly affected by the alkali pre-treatment concentration $(p<0.05)$. In conclusion, agar extracted in this study was considered acceptable for industrial application and the optimal conditions for extraction were found to be at $6 \%$ $\mathrm{NaOH}$ at $70^{\circ} \mathrm{C}$ for 2 hours.
\end{abstract}

Key words: Seaweed, Melanothamnus somalensis, agarophytes, agar extraction, alkali pre-treatment, FTIR.

\section{Introduction}

In seaweeds, agar fulfils a role similar to that of cellulose in terrestrial plants, but it has a more flexible structure to resist currents and waves motion. Agar as a useful material for humans is well known in the far East for more than 300 years [1, 2]. Recently, agar chemistry is receiving great attention because of the increase of biopolymers role in different biochemical, biomedical and industrial applications [3]. Examples of applications include gelling agents for liquid and spread foods, soft texture confectionery, fat replacers and cryoprotectants reduce damage during freezing-thawing cycles of vegetables [4]. Its use as food ingredient accounts for $80 \%$ of its consumption and the remaining is utilized for biotechnological

Corresponding author: Ahmed Ali Al-Alawi, associate professor, research field: food chemistry. E-mail: ahmed543@squ.edu.om. applications [5]. Structurally, agar is a high molecular weight polysaccharide extracted from red algae (rhodophyta) and consists of two different components - agarose and agaropectin. Agarose is a neutral polysaccharide with a linear structure of repeated units of dissaccharide agarobiose, which consists of D galactose and 3,6-L-anhydrogalactose (3,6 AG). Agaropectin, on the other hand, is an acid polysaccharide containing sulfate ester, pyruvic acid and D-glucuronic acid in addition to agarobiose [6]. Gel properties of agar, such as gel strength and gelling temperatures are largely influenced by type and quantity of the chemical substituents as well as molecular weight of the polysaccharide [7] which in turn is dependent on species, environmental conditions, physiological factors and methods of extraction $[6,8]$.

The most common way to extract agar is by boiling the seaweed in hot water, filtering it off and then 
separating the polysaccharide by a freezing and thawing cycle to eliminate water [5]. Although the general aspects of the extraction process are known, studies are still needed to optimize extraction conditions to increase and improve the yield and quality of the product $[5,9]$. In addition, the molecular structure of agar polysaccharides, particularly the type and location of sulfate esters, appears to be species-specific. For instance, agar obtained from Gelidium species is easily extracted with boiling water. In other species, a pre-treatment with alkali $(\mathrm{NaOH})$ is required for the de-sulfation of the native agar. This enhances extraction of polysaccharide from the cell wall and causes the formation of a 3,6 AG bridge, which in turn increases the gel strength of the treated agar $[2,4]$. Besides alkali treatment, extraction time was also found to play a role in yield and quality of the agar [5]. Although this molecular modification is required to meet commercial agar specifications, it may produce agars with different degrees of sulfate hemiester substitution. Thus, the final agar yield and chemical characteristics will depend on the severity of the treatment (alkali concentration, temperature and duration). Therefore, alkaline treatment variables must be optimized for each species to achieve the highest de-sulfation while inhibiting the yield losses during the treatment $[4,5,9]$.

The southern part of Oman (Dhofar province), which is well known for its long beaches, is rich in seaweeds, but their economic potential is largely unknown mainly due to limited data in the literature about seaweeds grown in this area. A comprehensive study conducted in 1998 by the Omani government on seaweeds identified several species that could have economical potentials [10]. Out of the main identified indigenous species of the agarophyte red algae that potentially have commercial value as raw material for agar extraction, Melanothamnus somalensis was selected for investigation [11, 12]. It was selected because it is widely spread in the region and its collection is very simple. Hence, this paper aims to study the effect of extraction conditions on gel quality in order to identify the best conditions for extraction. For this purpose, three aspects of the pre-treatment (alkali concentration, duration and temperature) were studied in terms of agar yield and chemical properties. Consequently, based on the effect of extraction pre-treatment, the optimum level was estimated in order to contribute with more information in relation to chemical properties and the possible use of this species for agar industry. To the best of the knowledge, this is the first publication on the chemical characterization of agar present in Melanothamnus somalensis from Oman.

\section{Materials and Methods}

All standards, chemicals and solvents were purchased from Sigma-Aldrich Co. Ltd. and all were of analytical grade unless otherwise specified. All solutions were prepared with deionized water. Each sample was analyzed at least in duplicate.

\subsection{Sample Collection and Pre-treatment}

Based on preliminary surveys of potential study sites [11], samples of red seaweed species Melanothamnus somalensis were collected by specialists from the identified site of the southern coast of Oman, Mirbat (16 59'28.7" N, 5441'27.7" E). The samples were transferred to the laboratory in cold boxes, washed with running fresh water, cleaned from extraneous matter (other seaweeds and invertebrates, mollusks and crustaceans) and then sun dried for three days. The dried samples were packed in plastic bags and stored in a refrigerator at $4{ }^{\circ} \mathrm{C}$ until further processing. For extraction pre-treatment, $20 \mathrm{~g}$ of the sundried samples were hydrated by soaking overnight in $1 \mathrm{~L}$ of de-ionized water at ambient temperature. Then, it was soaked in $100 \mathrm{~mL}$ of acetone/methanol (1:1) mixture for discoloration.

\subsection{Extraction Method}

The industrial alkaline pre-treatment extraction was 
performed according to Pereira et al. [13] with some modifications. The re-hydrated and discolourized sample was soaked in $1.5 \mathrm{~L}$ of alkaline solution of variable strength $(4 \%, 6 \%$ and $8 \% \mathrm{w} / \mathrm{v}$ of sodium hydroxide) and heated at different temperatures $\left(70^{\circ} \mathrm{C}\right.$, $75{ }^{\circ} \mathrm{C}$ and $\left.80^{\circ} \mathrm{C}\right)$ for different durations $(2 \mathrm{~h}, 2.75 \mathrm{~h}$ and $3.5 \mathrm{~h}$ ). Gentle stirring started after $1 \mathrm{~h}$ for every 15 min with a wooden spoon. The alkaline solution was then discarded and the algal material was coarse filtered (through 2 layers of cheesecloth), washed several times with de-ionized water to remove excess $\mathrm{NaOH}$. Then, the retained extract was re-dissolved in $500 \mathrm{~mL}$ of de-ionized water and $\mathrm{pH}$ was neutralized using $6 \mathrm{~N} \mathrm{HCl}$. The seaweed was then heated to $90{ }^{\circ} \mathrm{C}$ for $1 \mathrm{~h}$ with continuous gentle stirring. The resulting hot mixture was then filtered using double layer of cheesecloth in strainer followed by vacuum assisted filtration using GF/D, GF/C filter paper. Then, the $\mathrm{pH}$ of the collected liquid was again adjusted to 8 , kept overnight $(14 \mathrm{~h})$ at $4{ }^{\circ} \mathrm{C}$ in a refrigerator until gelled and then, dried in the oven at $60{ }^{\circ} \mathrm{C}$ for $12 \mathrm{~h}$ to concentrate the extract. Finally, the concentrated extract was placed in a plastic container and kept in a freezer for $16 \mathrm{~h}$. The frozen extract was freeze dried using an Edwards K4 Freeze Drier (Corawky, Crawley and England), milled by using an electrical mill (Black and Decker) to pass through $500 \mu \mathrm{m}$ mesh and then, stored in a closed plastic container at room temperature until usage. The agar yield was determined and expressed as a percentage of the sun dried plant as in Eq. (1):

$$
\text { Agar yield }(\%)=\frac{\text { Agar dry weight }(\mathrm{g})}{\text { Seaweed dry weight }(\mathrm{g})} \times 100 \%
$$

For each combination of alkali concentration, temperature and pre-treatment duration were conducted of two replicates.

\subsection{FTIR (Fourior Transform Infrared) Analysis}

The extracted agar powder was analyzed by the method described by Al-Alawi et al. [12] using Magna 560 FTIR spectrometer (Thermo Nicolet, USA) equipped with ZeSn ATR cell. The powder was placed at the surface of the ATR crystal and IR spectrum of the sample was collected by averaging 128 scans at resolutions of 4 .

\subsection{Sulfate Content Determination}

Sulfate content was determined turbidimetrically with Barium chloride after acid hydrolysis as described by Dodgson [14]. The method involves preparation of Barium chloride-gelatin reagent by dissolving $2 \mathrm{~g}$ of gelatin in $400 \mathrm{~mL}$ of hot water $\left(60-70{ }^{\circ} \mathrm{C}\right)$ and then cooling to $4{ }^{\circ} \mathrm{C}$ for overnight. Then, $2 \mathrm{~g}$ of Barium chloride was dissolved in the resulting semigelatinous gelatin solution and then left to stand for 2-3 h. This reagent is stable for one week at $4{ }^{\circ} \mathrm{C}$. For the assay, $0.2 \mathrm{~mL}$ of $0.1 \% \mathrm{w} / \mathrm{v}$ agar solution was added to $3.8 \mathrm{~mL}$ of $4 \%$ trichloroacetic acid followed by $1 \mathrm{~mL}$ of the $\mathrm{BaCl}_{2}$-gelatin reagent. The reagents were mixed and then allowed to stand for $10-20 \mathrm{~min}$ at room temperature. Finally, the absorbance was measured at $360 \mathrm{~nm}$. The calibration curve was prepared with solutions of $\mathrm{K}_{2} \mathrm{SO}_{4}$ containing between $20 \mu \mathrm{g}$ and $200 \mu \mathrm{g}$ of $\mathrm{SO}_{4}{ }^{2-}$ ions.

\subsection{Molecular Weight Analysis}

The size exclusion chromatography experiment described by Alawi et al. [12] was employed for molecular weight determination. The analysis was carried on Agilent 1100 (Agilent, USA) instrument equipped with a waters ultrahydrogel linear column (waters corporation) and a differential refractive index detector (Agilent RID 1100). A $0.1 \mathrm{M} \mathrm{NaCl}$ solution was used as a dissolving solution as well as an elution solution. A sample size of $20 \mu \mathrm{L}$ of $0.1 \% \mathrm{w} / \mathrm{v}$ of agar solution was injected in the system at a flow rate of 1 $\mathrm{mL} / \mathrm{min}$. The temperature of the column compartment as well as the temperature of the detector flow cell was maintained constant at $40^{\circ} \mathrm{C}$ throughout the analysis.

\subsection{Statistical Analysis}

The statistical analysis was performed using the 
SPSS software for windows version 11.5. The data obtained are presented as mean \pm standard deviation. General Linear Model (GLM) for univariate analysis was used to determine the main and interactive effects of alkali pre-treatment on agar yield, molecular weight and sulfate content. When differences were found, a multiple post hoc Duncan's Multiple Range Test was applied. $\mathrm{P}$ values less than 0.05 was considered as statistically significant.

\section{Results and Discussion}

The yield, molecular weight and sulfate contents of agar extracted from Melanothamnus somalensis species at different extraction conditions are presented in Table 1. The results show that Melanothamnus somalensis seaweed gave yield in the range $18.73 \% \pm$ $0.64 \%$ to $38.14 \% \pm 16.02 \%$ depending on the extraction conditions. This range is in accordance with yields reported earlier from different seaweeds in the literature $[1,5,7,15-26]$. Furthermore, yields in the range $15 \%$ to $25 \%$ are considered acceptable yield for industrial applications [27, 28].

Evaluation of the effect of alkaline concentration on the yield using Duncan's Multiple Range analysis

Table 1 Properties of agar extracted from Melanothamnus somalensis under different alkali pre-treatment conditions.

\begin{tabular}{|c|c|c|c|c|c|}
\hline \multicolumn{3}{|c|}{ Treatment } & \multirow{2}{*}{ - Yield $(\% \mathrm{w} / \mathrm{w})^{1} \pm \mathrm{SD}$} & \multirow{2}{*}{$\mathrm{M}_{\mathrm{W}}($ Dalton $) \pm \mathrm{SD}$} & \multirow{2}{*}{ Sulfate $(\% \mathrm{w} / \mathrm{w})^{1} \pm \mathrm{SD}$} \\
\hline $\mathrm{NaOH}$ & Time (h) & Temperature $\left({ }^{\circ} \mathrm{C}\right)$ & & & \\
\hline \multirow{9}{*}{$4 \%$} & \multirow{3}{*}{2} & 70 & $24.94 \pm 0.49$ & $(12.30 \pm 0.42) \times 10^{5}$ & $9.62 \pm 0.14$ \\
\hline & & 75 & $24.04 \pm 3.88$ & $(12.30 \pm 0.00) \times 10^{5}$ & $9.12 \pm 0.28$ \\
\hline & & 80 & $25.71 \pm 5.06$ & $(11.80 \pm 0.14) \times 10^{5}$ & $9.32 \pm 0.00$ \\
\hline & \multirow{3}{*}{2.75} & 70 & $26.38 \pm 2.51$ & $(12.35 \pm 0.07) \times 10^{5}$ & $7.02 \pm 0.14$ \\
\hline & & 75 & $22.52 \pm 2.98$ & $(12.30 \pm 0.00) \times 10^{5}$ & $10.12 \pm 0.28$ \\
\hline & & 80 & $22.59 \pm 1.18$ & $(11.75 \pm 0.07) \times 10^{5}$ & $8.62 \pm 0.42$ \\
\hline & \multirow{3}{*}{3.5} & 70 & $23.11 \pm 1.11$ & $(12.45 \pm 0.21) \times 10^{5}$ & $8.72 \pm 0.28$ \\
\hline & & 75 & $18.73 \pm 0.64$ & $(11.85 \pm 0.07) \times 10^{5}$ & $8.72 \pm 0.85$ \\
\hline & & 80 & $21.60 \pm 0.54$ & $(12.13 \pm 0.04) \times 10^{5}$ & $9.72 \pm 0.85$ \\
\hline \multirow{9}{*}{$6 \%$} & \multirow{3}{*}{2} & 70 & $38.11 \pm 0.87$ & $(12.15 \pm 0.21) \times 10^{5}$ & $9.62 \pm 0.14$ \\
\hline & & 75 & $32.67 \pm 2.82$ & $(11.95 \pm 0.35) \times 10^{5}$ & $7.92 \pm 0.57$ \\
\hline & & 80 & $29.85 \pm 2.49$ & $(11.55 \pm 0.49) \times 10^{5}$ & $8.62 \pm 0.14$ \\
\hline & \multirow{3}{*}{2.75} & 70 & $35.01 \pm 0.53$ & $(12.30 \pm 0.14) \times 10^{5}$ & $8.72 \pm 0.57$ \\
\hline & & 75 & $24.89 \pm 2.94$ & $(10.75 \pm 0.64) \times 10^{5}$ & $6.62 \pm 0.14$ \\
\hline & & 80 & $24.10 \pm 6.17$ & $(10.80 \pm 0.28) \times 10^{5}$ & $7.82 \pm 0.42$ \\
\hline & \multirow{3}{*}{3.5} & 70 & $27.01 \pm 2.79$ & $(12.10 \pm 0.14) \times 10^{5}$ & $8.12 \pm 0.28$ \\
\hline & & 75 & $38.14 \pm 16.02$ & $(11.70 \pm 0.42) \times 10^{5}$ & $10.02 \pm 0.71$ \\
\hline & & 80 & $28.00 \pm 10.64$ & $(10.75 \pm 0.49) \times 10^{5}$ & $8.82 \pm 0.42$ \\
\hline \multirow{9}{*}{$8 \%$} & \multirow{3}{*}{2} & 70 & $21.86 \pm 0.73$ & $(8.60 \pm 2.40) \times 10^{5}$ & $8.22 \pm 0.14$ \\
\hline & & 75 & $31.53 \pm 0.14$ & $(9.95 \pm 0.35) \times 10^{5}$ & $9.02 \pm 0.42$ \\
\hline & & 80 & $32.74 \pm 2.87$ & $(10.75 \pm 0.21) \times 10^{5}$ & $6.72 \pm 0.57$ \\
\hline & \multirow{3}{*}{2.75} & 70 & $26.94 \pm 0.37$ & $(10.95 \pm 0.07) \times 10^{5}$ & $7.82 \pm 0.14$ \\
\hline & & 75 & $26.53 \pm 1.70$ & $(10.40 \pm 0.28) \times 10^{5}$ & $8.72 \pm 0.57$ \\
\hline & & 80 & $27.58 \pm 11.59$ & $(10.45 \pm 0.92) \times 10^{5}$ & $5.42 \pm 0.42$ \\
\hline & \multirow{3}{*}{3.5} & 70 & $23.16 \pm 0.64$ & $(9.70 \pm 0.42) \times 10^{5}$ & $7.52 \pm 0.57$ \\
\hline & & 75 & $29.42 \pm 0.29$ & $(10.55 \pm 0.92) \times 10^{5}$ & $9.02 \pm 0.42$ \\
\hline & & 80 & $24.44 \pm 1.98$ & $(10.80 \pm 0.28) \times 10^{5}$ & $6.02 \pm 0.71$ \\
\hline
\end{tabular}

${ }^{1}$ Dry basis. 


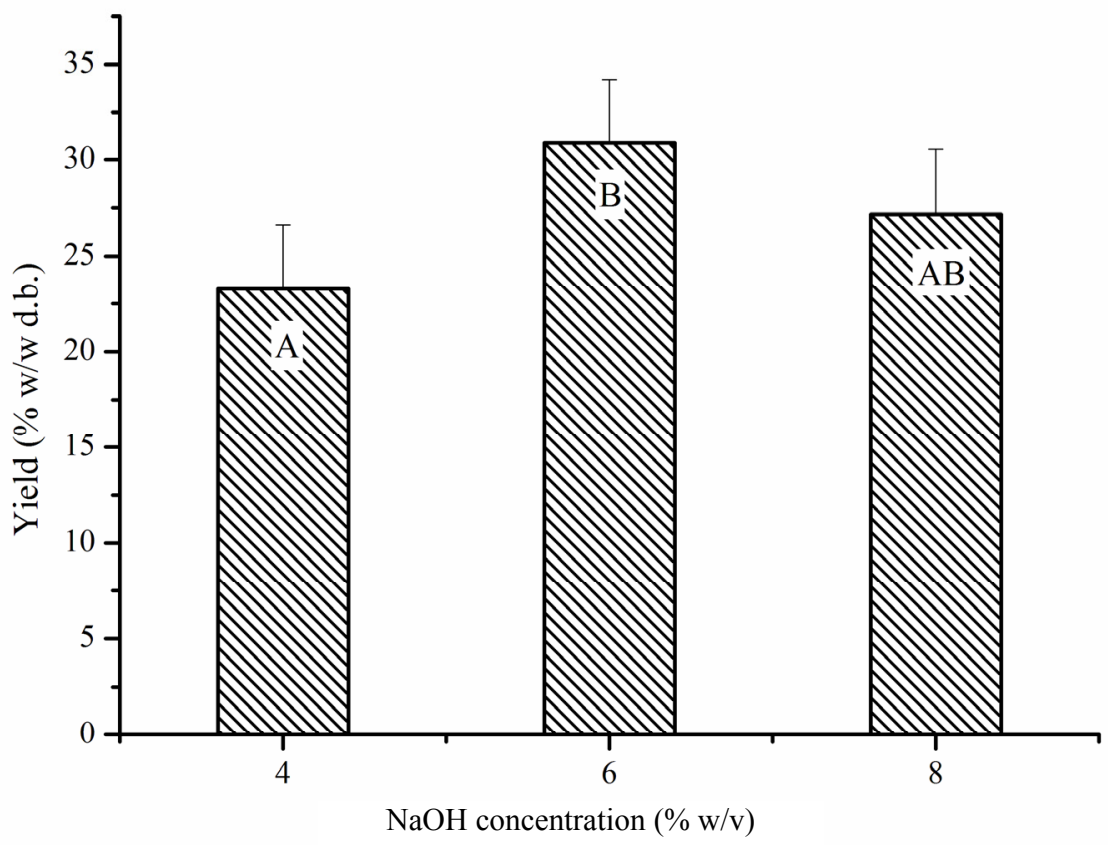

Fig. 1 Effects of alkali concentration on yield of agar extracted from Melanothamnus somalensis (means with the same letter are not significantly different $(\alpha=\mathbf{0 . 0 5}))$.

showed that there is significant increase in the yield when the $\mathrm{NaOH}$ concentration increased from $4 \%$ to $6 \%(\mathrm{P}<0.05)$ and the yield increased from $23.29 \% \pm$ $2.94 \%$ to $30.86 \% \pm 7.29 \%$ respectively (Fig. 1 ). On the other hand, no significant difference was observed between alkali-treated concentration of $8 \%$ and other concentrations. This finding suggests that alkali treatment was suitable to be performed at $6 \%$ and there is no need to use stronger concentration treatment. Performing the same statistical test on time and temperature variables showed no significant differences among alkali treatments $(\mathrm{P}>0.05)$.

This is in agreement with many previous results where opposite trends were observed for the agar yield with the increase in alkali concentration [1, 9, 29-32]. However, Villanueva et al. [8] reported that extraction of agar from Gracilaria vermiculophylla with alkali concentration (2\%-8\%) gave higher agar yield at higher alkali concentrations (24\%-33\%). These dissimilarities support the hypothesis that extraction properties are species specific and should be separately determined $[4,9]$. In the case of the species under investigation (Melanothamnus somalensis), low alkaline concentration in the pre-treatment step was found to be not suitable for maximum agar extraction, which is mainly due to the robust nature and tough almost "rubbery" dense branches of the plant [11]. Furthermore, yield reduction at higher alkaline concentration appears to be associated with the possible degradation and losses of the polysaccharide in the alkaline solution $[8,9,19,31-35]$. Moreover, Oza et al. [36] noticed that alkali concentration of about $10 \%(\mathrm{w} / \mathrm{v})$ causes a complete leach out of the agar polysaccharide.

In general, the agar yields of Melanothamnus somalensis were comparable to those found in the literature. These values which were obtained after the alkali treatment were more than double of recommended for industrial purposes $(>8.0 \%)$ using agar producing species [2, 29].

On the basis of information presented in this study and previous reports, agar yield could be stimulated by manipulating each extraction variable although exogenous factors, such as species, location and environmental parameters and stage of the life-cycle [28] have critical roles to play in maximizing agar 
extraction [15]. The different responses of different species to manipulated parameters do not allow establishing a constant method for agar extraction [9, 19].

The molecular weights of extracted agar obtained from Melanothamnus somalensis are shown in Table 1. These values, which ranged between $12.45 \pm 0.21 \times$ $10^{5}$ to $8.60 \pm 2.40 \times 10^{5} \mathrm{Da}$ are above the range of molecular weights extracted from other species such as Gracilaria, Gelidium and Hydropuntia [3, 7, 8, 27, 35, 37-44].

The careful control of $\mathrm{pH}(>7)$, which is applied in the post alkali treatment step ensured minimum degradation of the acid sensitive agar polysaccharide [33]. The higher molecular weight ranges obtained in this study could be attributed to low growth rates of plants as influenced by low light intensity in the area due to cloud coverage as demonstrated by Sousa-Pinto et al. [11, 38].

Molecular weights of the extracted agars showed a significant variation only with alkaline concentration $(\mathrm{p}<0.05)$ where the weights decreased with the increase in alkali concentration (Table 1). The greatest average molecular weight: $12.14 \pm 0.29 \times 10^{5} \mathrm{Da}$, which was observed for agar sample extracted at $4 \%$ NOH pre-treatment and the lowest was $10.24 \pm 0.99 \times$ $10^{5} \mathrm{Da}$ for the agar polymer obtained by $8 \% \mathrm{NaOH}$ pre-treatment, while agar extracted with $6 \% \mathrm{NaOH}$ pre-treatment had $\mathrm{M}_{\mathrm{W}}$ of $11.56 \pm 0.68 \times 10^{5} \mathrm{Da}$ (Fig. 2).

This adverse effect on molecular weight with increase in $\mathrm{NaOH}$ concentration is in good agreement with those found in other studies [33, 35]. The decline of agar molecular weight in this study appears to be associated with the decomposition of polysaccharides during alkali treatment. Duncan's Multiple Range Test on the means of agar molecular weight $\left(\mathrm{M}_{\mathrm{W}}\right)$ with alkali concentration treatment is presented in Fig. 2.

The synergistic interaction between alkaline concentration and temperature was found to be significant, implying a significant influence of one to the performance of the other. Fig. 3 presents the

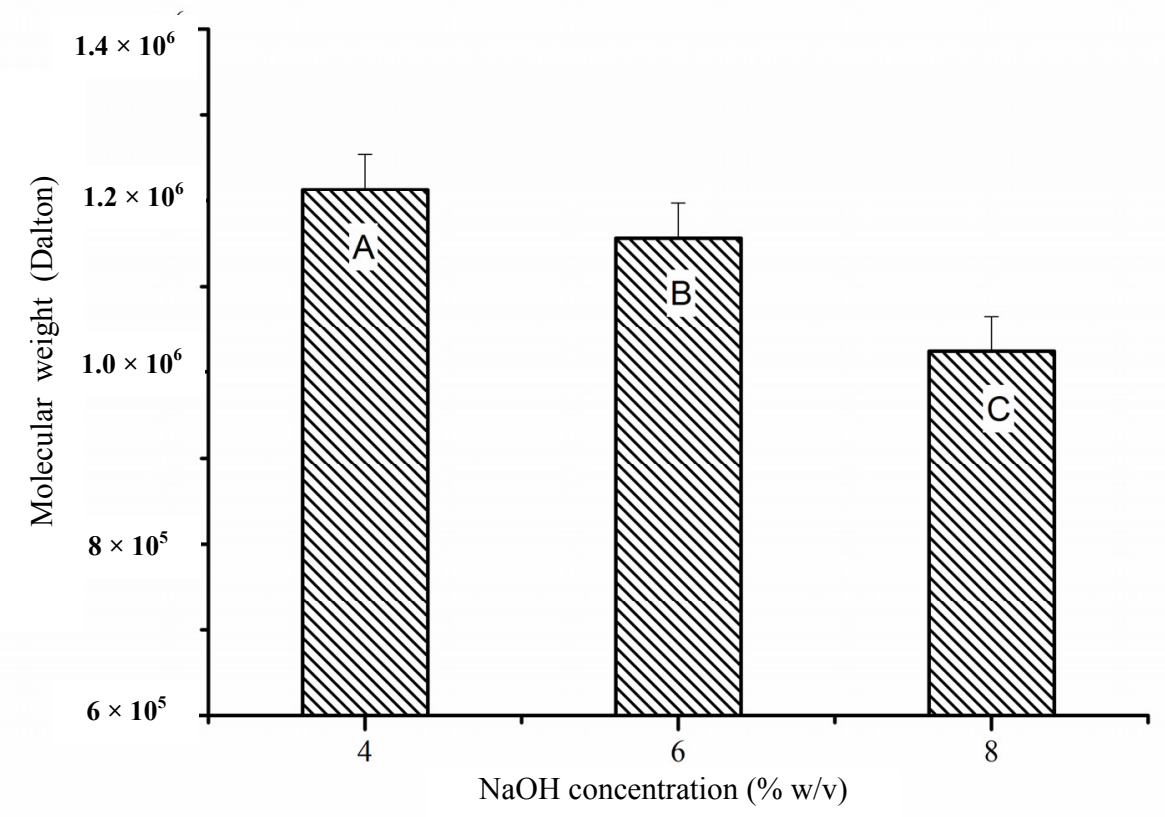

Fig. 2 Effect of alkali concentration on $\mathrm{M}_{\mathrm{W}}$ of agar extracted from Melanothamnus somalensis (means with the same letter are not significantly different $(\alpha=0.05))$. 


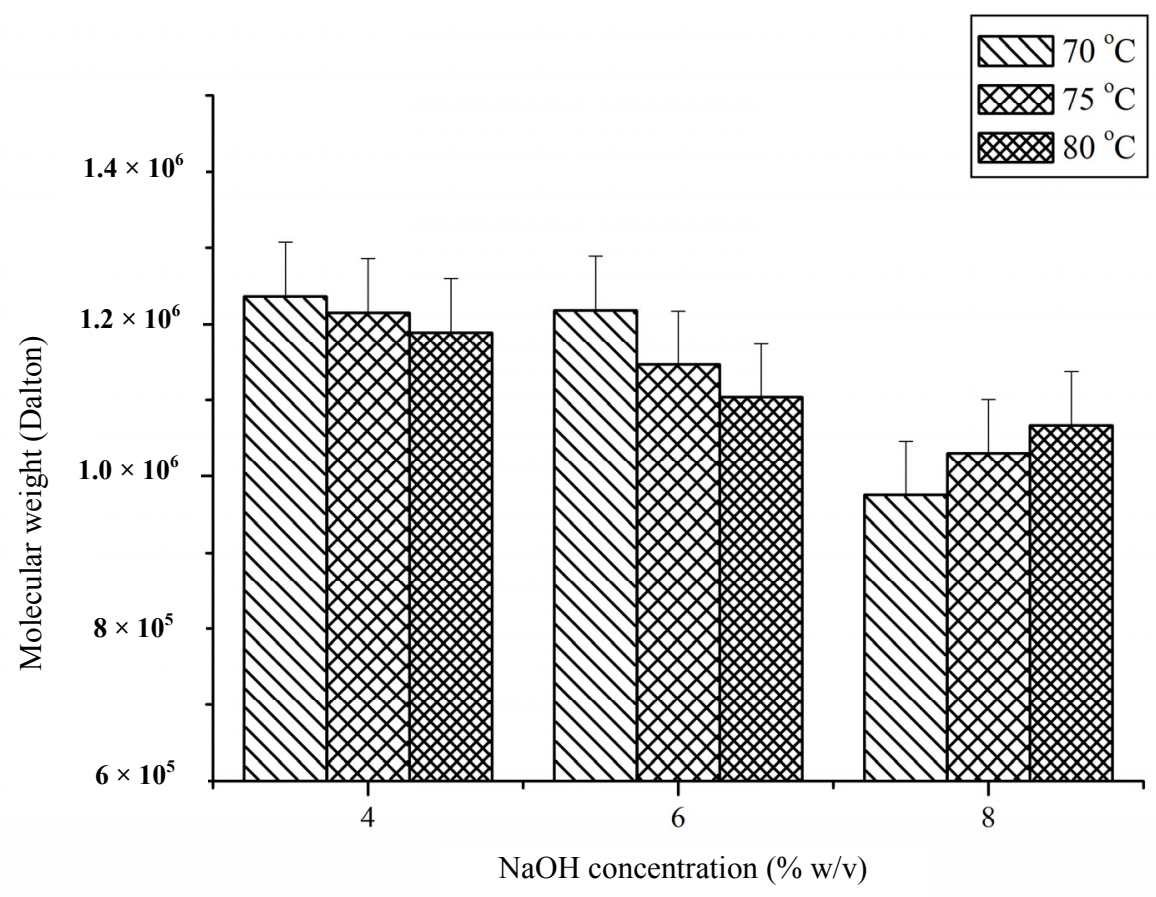

Fig. 3 Interaction effect of alkali concentration and temperature on $\mathrm{M}_{\mathrm{W}}$ of agar extracted from Melanothamnus somalensis.

negative relationship between alkaline concentration and temperature in one hand and agar molecular weight in the other hand. A sharp descending trend of efficiency by increasing alkali concentration and pre-treatment temperature was noticeable with alkaline concentrations of $6 \%$ and temperature of $70{ }^{\circ} \mathrm{C}$. According to P-value, the pre-treatment has the most significant effect at this interaction.

Fig. 4 shows the FTIR spectra of a commercial agar (amresco, CAS\# 9002-18-0) and the extracted agar from Melanothamnus somalensis red seaweed are at different extraction conditions. Table 2 summaries FTIR results which reveal the presence of most characteristic bands of polysaccharides from red seaweeds.

The band at $1,370 \mathrm{~cm}^{-1}$ corresponds to ester sulfate groups in general. The absorbance band at $1,250 \mathrm{~cm}^{-1}$ is a result of asymmetric stretching of sulfate ester group $\mathrm{S}=\mathrm{O}$. Moreover, the band at $1,065 \mathrm{~cm}^{-1}$ shows the skeletal mode of the galactan [45]. The peak at $930 \mathrm{~cm}^{-1}$ is due to the vibration of the C-O-C bridge of 3,6 -anhydro- $\alpha$-L-galactose [13]. This band is the most representative of the agar family since the infrared spectra of the other polysaccharides contained in red algae, such as cellulose and xylans which do not exhibit absorptions at this wave numbers. The region between $900 \mathrm{~cm}^{-1}$ and $800 \mathrm{~cm}^{-1}$ gives information about the position of sulfate group in the agar structure. In the sample under study, the signal at 870 $\mathrm{cm}^{-1}$ was found to be indicative of the presence of sulfate group on C6 of $\alpha$-L-galactose [46]. According to Rees [47] and Ciancia et al [48], the alkaline treatment of agar molecules eliminates the unstable axial sulfate groups at C- 6 of the $\alpha$-L-galactose unit when the hydroxyl group at $\mathrm{C}-3$ is free, giving rise to a more stable 3,6-anhydro- $\alpha$-L-galactose [5, 49]. Therefore, survival of sulfate ester group on C6 of $\alpha$-L-galactose means that the $\mathrm{C}-3$ is substituted with probably a sulfate group.

The signal at $855 \mathrm{~cm}^{-1}$ is assigned to the sulfate in C-4 from $\beta$-D-galactose [30, 43, 46, 50-52]. The band at $820 \mathrm{~cm}^{-1}$ is characteristic of 6 -sulfate group of $\beta$-D-galactose unit $[43,53,54]$. It was detected as a shoulder in the agar commercial sample and as a 


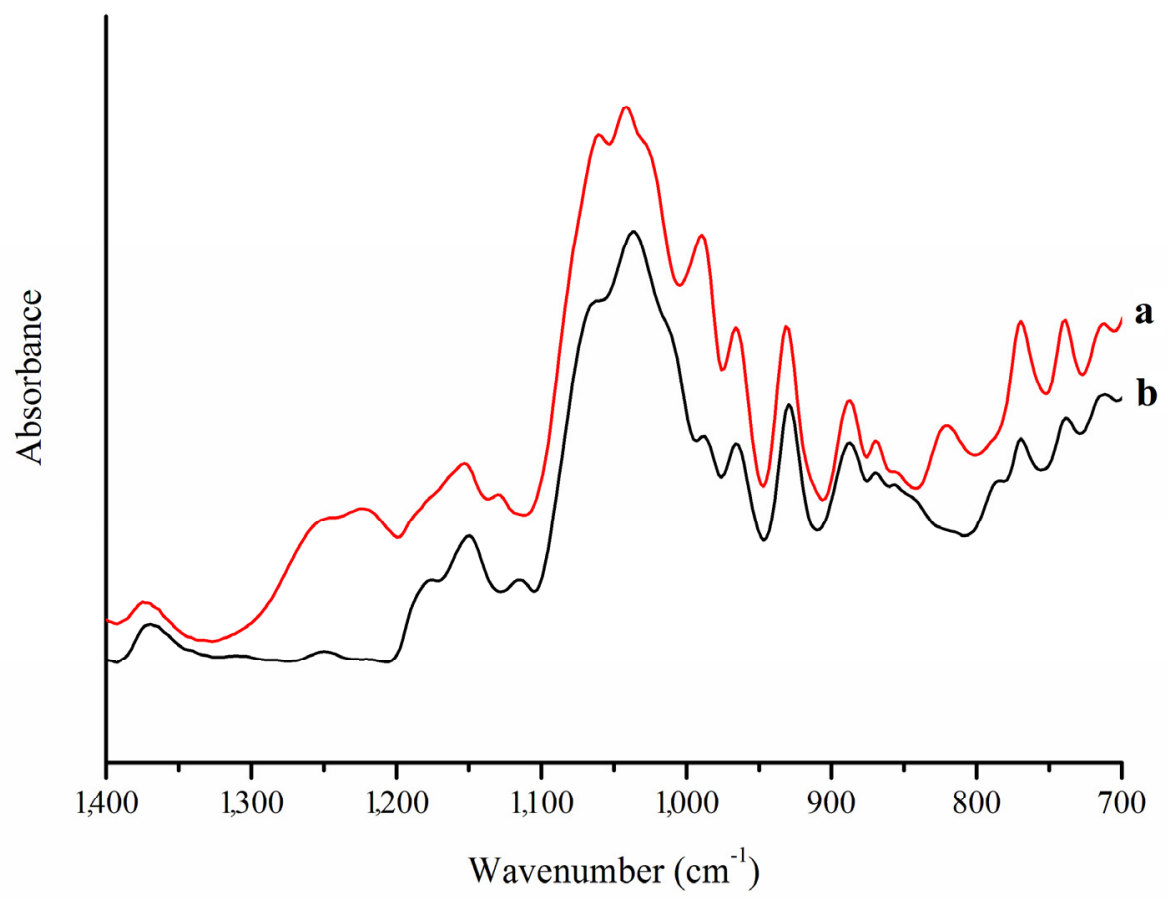

Fig. 4 Infrared spectra of agar extracted from Melanothamnus somalensis at $8 \% \mathrm{NaOH}, 2$ h and $80{ }^{\circ} \mathrm{C}$ condition (a) compared to commercial agar (b).

Table 2 Assigned signals in the FTIR spectra of agar extracted from Melanothamnus somalensis [13, 30, 46, 51-52].

\begin{tabular}{llll}
\hline Wavenumber $\left(\mathrm{cm}^{-1}\right)$ & Assignment & Commercial agar & Extracted agar \\
\hline 790 & Characteristic band of agar-type polysaccharides & Present & Not present \\
805 & Sulfate group on C-2 of 3,6-anhydro- $\alpha$-L-galactose & Not present & \\
820 & Sulfate group on C-6 of $\beta$-D-galactose & Present & \\
830 & Sulfate group on C-2 of $\beta$-D-galactose & Not present & \\
855 & Sulfate group on C-4 of $\beta$-D-galactose & Present & \\
870 & Sulphate group on C-6 of $\alpha$-L-galactose & Present & \\
905 & Sulphate group on C-2 of 3,6-anhydro- $\alpha$-L-galactose & Not present & Strong \\
930 & Vibration of the C-O-C bridge of 3,6-anhydro- $\alpha$-L-galactose & Present & Weak \\
$1,200-1,300$ & S = O ester sulfate & & \\
\hline
\end{tabular}

distinct band in alkaline treated extracted agar samples of the Melanothamnus somalensis. The absence of absorption bands at $830 \mathrm{~cm}^{-1}$ and $805 \mathrm{~cm}^{-1}$ shows lack of sulfation on $\mathrm{C} 2$ of the ( $\beta-\mathrm{D}$ and $\alpha-\mathrm{L})$-galactose units and on $\mathrm{C} 2$ of the 3,6-anhydro- $\alpha$-L-galactose respectively [46]. Based on the information gathered from FTIR spectra signals, the corresponding chemical structure of the extracted agar from Melanothamnus somalensis (after the 3,6 AG formation) is shown in Fig. 5.
All treatments without exception showed similar FTIR profile irrespective of the condition. The most interesting observation is survival of sulfate ester group on $\mathrm{C} 6$ of $\alpha$-L-galactose even at the most harsh condition in the current study $\left(80{ }^{\circ} \mathrm{C}, 3.5 \mathrm{~h}\right.$ and $8 \%$ $\mathrm{NaCl}$ w/v).

In the present study, the sulfate content of the agar extracts from different treatments is shown in Table 1. In general, all treatments showed agars with high sulfate content, which ranged from $5.42 \% \pm 0.42 \%$ 


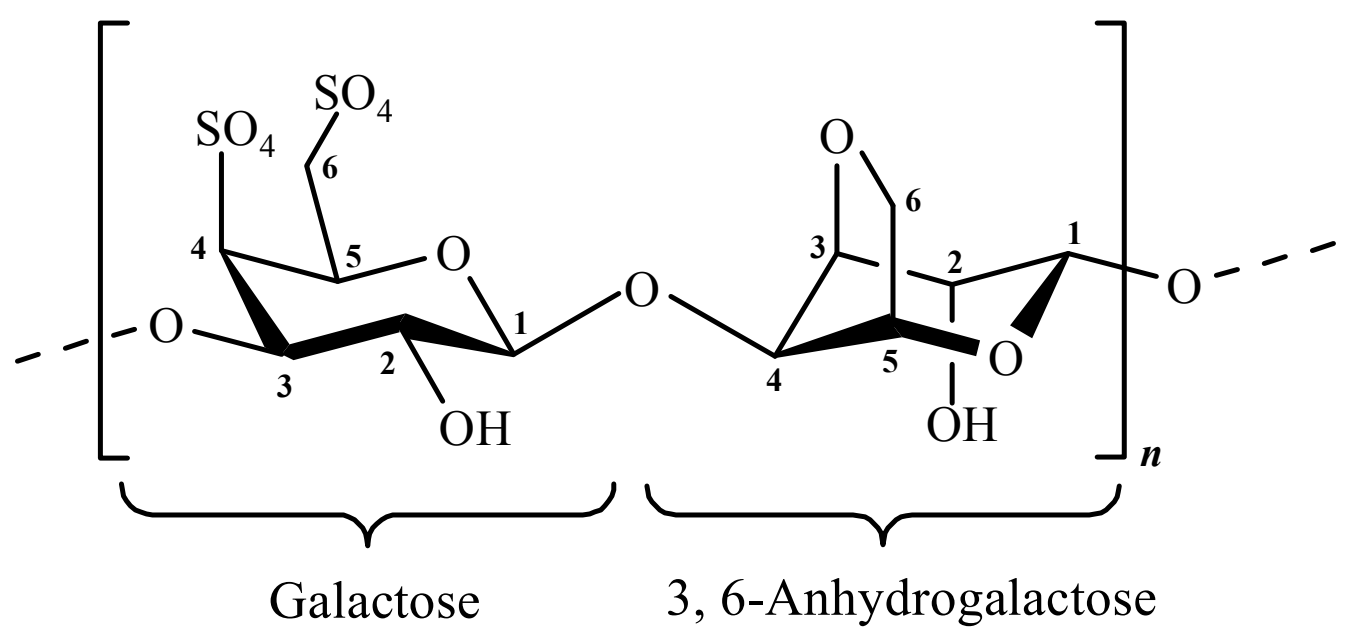

Fig. 5 The suggested structure of agar extracted from Melanothamnus somalensis showing carbon numbering (C1-C6).

to $10.12 \% \pm 0.28 \%$. These results are higher than those found in other species such as Gracilaria, Gelidium and Gelidiella [6-9, 20, 31, 38, 41, 49, 54]. For example, the sulfate content of native agar extracted from Gracilaria was found to be in the range of $1.3 \%$ to $14.3 \%[9,55]$.

The high sulfate content in the extracted agar samples indicates a probable presence of sulfate in other positions in addition to 6-position of L-galactose [1] as found by the FTIR spectra. The high sulfate content in Melanothamnus somalensis samples is attributed to the environmental conditions at the area of seaweed collection especially elevated climatic temperatures $\left(27-28{ }^{\circ} \mathrm{C}\right)$ which made the agar to contain more sulfates and less 3,6 AG $[2,56]$.

Furthermore, the amount of sulfate contents decreased gradually with increase in alkali concentration. It is worth mentioning, that sulfate contents in the extracted agar was found to be statistically different $(\mathrm{P}<0.05)$ with regard to all extraction conditions $(\mathrm{NaOH}$ concentration, temperature and treatment duration time) and their interaction (Figs. 6 and 7). These results are in agreement with many previous studies [4, 23, 33, 49, 54]. For example, Heydari et al [2] reports that maximum amount of sulfate can be found in the mildest pre-treatment conditions. By increasing alkali concentration and pre-treatment temperature, the amount of sulfate existing in the biopolymer can be reduced. Moreover, the alkali concentration has a higher impact on the trend of sulfate variations than any other extraction variable.

The international food market currently requires sulfate content less than 4\%, usually $1.5 \%-2.5 \%$ [29]. In the current study, the outcome is above the acceptable range of the international market.

Earlier investigations from red algae extracts showed that this value slightly varies depending on raw material and differences in processing conditions, particularly on duration of washing of the final product. Prolonged water elution of the galactan preparations reduces sulfate content (high-charged fractions get faster detached), but this process is disadvantageous for practical applications [57].

\section{Conclusion}

The effect of different conditions of alkali pre-treatment on chemical properties of agar extracted from red seaweed Melanothamnus somalensis and collected from the southern area of Oman was investigated. In conclusion, this sulfated polysaccharide is a promising agent to be evaluated for application in industry as its yield is between $15 \%$ and $25 \%$, which is considered to be in the industrial acceptable range. Extracted agar studied by FTIR exhibits the characteristic bands of agaroclloids showing sulfate 


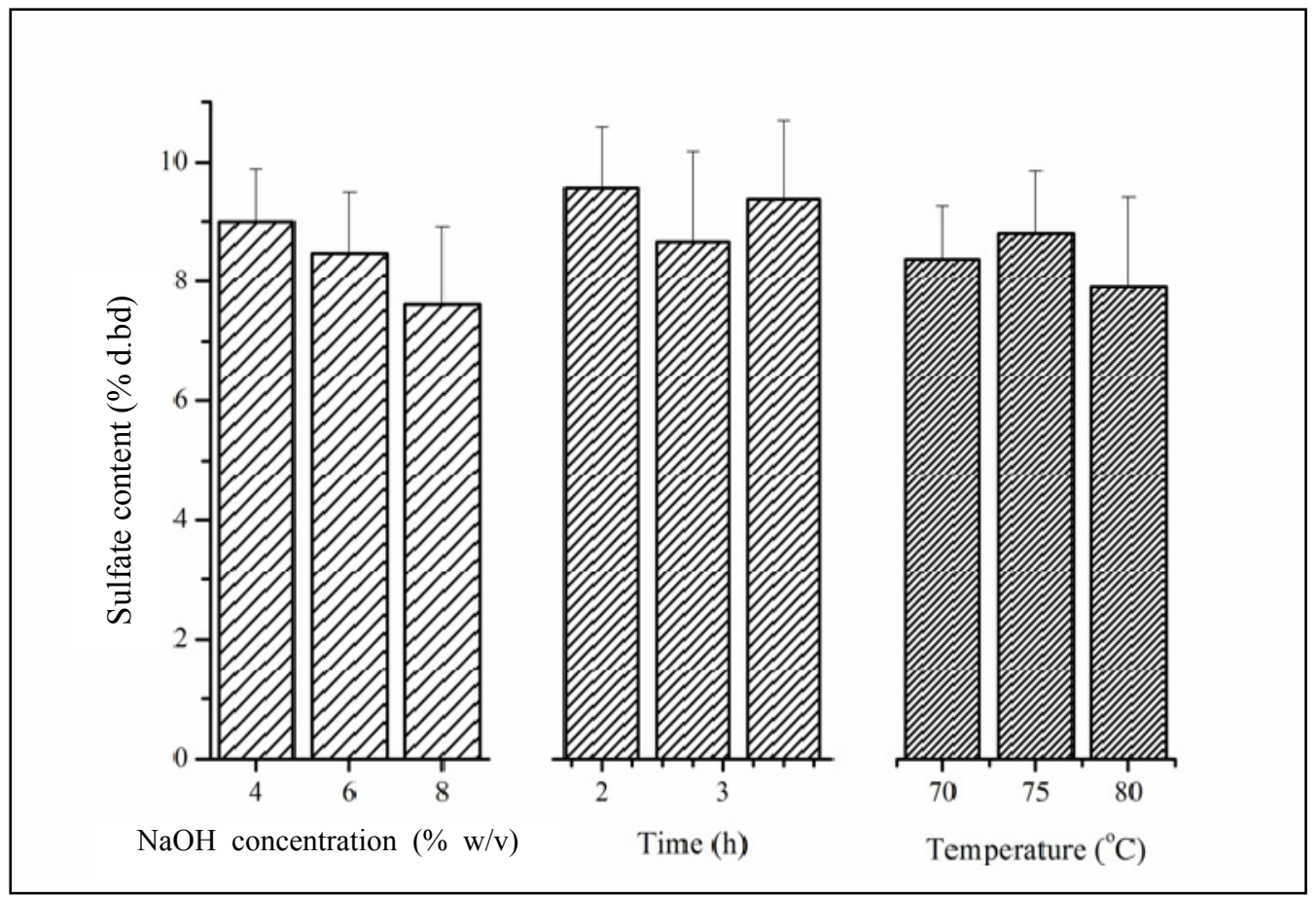

Fig. 6 Sulfate content of agar extracted from Melanothamnus somalensis at different conditions (significant difference $\mathbf{p}<0.05$ ).

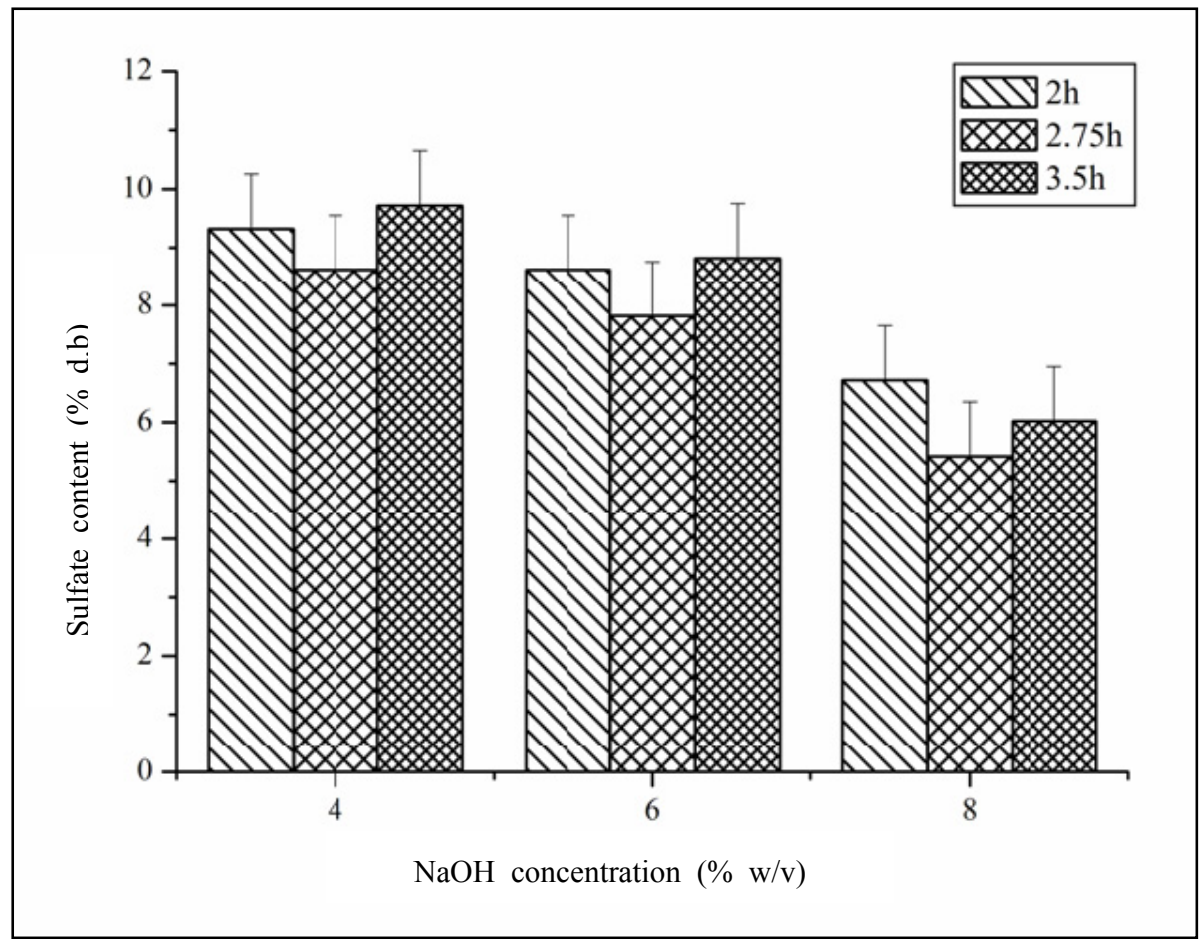

Fig. 7 Sulfate content of agar extracted from Melanothamnus somalensis at different conditions at $80^{\circ} \mathrm{C}$.

in $\mathrm{C} 4$ and $\mathrm{C} 6$ of galactose, vibration of the $\mathrm{C}-\mathrm{O}-\mathrm{C}$ bridge of 3,6 anhydro-L-galactose and no sulphate group were found on both $\mathrm{C} 2$ of Sulfate galactose and C2 3,6-anhydrogalactose. Furthermore, the optimal conditions for agar extraction with alkali pre-treatment in this study were obtained with $6 \% \mathrm{NaOH}$ at $70{ }^{\circ} \mathrm{C}$ for 2 hours. However, further studies are needed to explore the high amount of sulfate, which affects the 
final quality of the product.

\section{Acknowledgment}

The authors would like to thank Sultan Qaboos University for supporting this research in the area of developing functional foods and health supplements project. In addition, financial support provided by Sultan Qaboos University under the strategic research project (SR/AGR/FOOD/11/01) is greatly acknowledged.

\section{References}

[1] Marinho-Soriano, E. 2001. "Agar Polysaccharides from Gracilaria Species (Rhodophyta, Gracilariaceae)." Journal of Biotechnology 89 (1): 81-4.

[2] Heydari, M., Nematollahi, M. A., Motamedzadegan, A., Hosseini-Parvar, S. H., and Hosseini, S. V. 2014. "Optimization of the Yield and Quality of Agar from Gracilariopsis Persica." Bulletin of Environment, Pharmacology and Life Sciences 3 (3): 33-40.

[3] Trivedi, T. J., and Kumar, A. 2014. "Efficient Extraction of Agarose from Red Algae Using Ionic Liquids." Green and Sustainable Chemistry 4 (November): 190-201.

[4] Li, H., Huang, J., Xin, Y., Zhang, B., Jin, Y., and Zhang, W. 2009. "Optimization and Scale-Up of a New Photobleaching Agar Extraction Process from Gracilaria Lemaneiformis." Journal of Applied Phycology 21 (2): 247-54.

[5] Arvizu-Higuera, D. L., Rodriguez-Montesinos, Y. E., Murillo-Alvarez, J. I., Munoz-Ochoa, M., and Hernandez-Carmona, G. 2008. "Effect of Alkali Treatment Time and Extraction Time on Agar from Gracilaria Vermiculophylla." Journal of Applied Phycology 20 (5): 515-9.

[6] Marinho-Soriano, E., and Bourret, E. 2005. "Polysaccharides from the Red Seaweed Gracilaria Dura (Gracilariales, Rhodophyta)." Bioresource Technology 96 (3): 379-382.

[7] Romero, J. B., Villanueva, R. D., and Montano, M. N. E. 2008. "Stability of Agar in the Seaweed Gracilaria Eucheumatoides (Gracilariales, Rhodophyta) during Postharvest Storage." Bioresource Technology 99 (17): 8151-8155.

[8] Villanueva, R. D., Sousa, A. M. M., Gonçalves, M. P., Nilsson, M., and Hilliou, L. 2010. "Production and Properties of Agar from the Invasive Marine Alga, Gracilaria Vermiculophylla (Gracilariales, Rhodophyta)." Journal of Applied Phycology 22 (2): 211-220.

[9] Yousefi, M. K., Islami, H. M., and Filizadeh, Y. 2013.
"Effect of Extraction Process on Agar Properties of Gracilaria Corticata (Rhodophyta) Collected from the Persian Gulf." Phycologia 52 (6): 481-487.

[10] OSP. 1998. Oman Seaweed Project, First Status Report to Ministry of Agriculture and Fisheries, Marine Science and Fisheries Centre, Sultanate of Oman. Rome: Berardi and Associate.

[11] Jupp, B. 2002. Guidebook to the Seaweeds of the Sultanate of Oman. Sultanate of Oman: Mazoon Printing.

[12] Al-Alawi, A. A., Al-Marhubi, I. M., Al-Belushi, M. S. M., and Soussi, B. 2011. "Characterization of Carrageenan Extracted from Hypnea Bryoides in Oman." Marine Biotechnology (NY) 13 (5): 893-9.

[13] Pereira, L., Sousa, A., Coelho, H., Amado, A. M., and Ribeiro-Claro, P. J. A. 2003. "Use of FTIR, FT-Raman and 13C-NMR Spectroscopy for Identification of Some Seaweed Phycocolloids." Biomolecular Engineering 20 (4): 223-8.

[14] Dodgson, K. S. 1961. "Determination of Inorganic Sulphate in Studies on the Enzymic and Non-enzymic Hydrolysis of Carbohydrate and Other Sulphate Esters." Biochemical Journal 78 (February): 312-9.

[15] Hoyle, M. 1978. "Agar Studies in Two Gracilaria Species (G. Bursapastoris (Gmelin) Silva and G. Coronopifolia J. Ag.) from Hawaii. II. Seasonal Aspects." Botanica Marina 21 (6): 347-52.

[16] Hurtado-Ponce, A., and Umezaki, I. 1988. "Physical Properties of Agar Gel from Gracilaria (Rhodophyta) of the Philippines." Botanica Marina 31 (2): 171-4.

[17] Chirapart, A., and Ohno, M. 1993. "Seasonal Variation in the Physical Properties of Agar and Biomass of Gracilaria sp. (Chorda Type) from Tosa Bay, Southern Japan.” Hydrobiologia 260/261 (1): 541-547.

[18] Pondevida, H. B., and Hurtado-Ponce, A. Q. 1996. "Assessment of Some Agarophytes from the Coastal Areas of Iloilo, Philippines: II. Seasonal Variations in the Agar Quality of Gracilaria Changii, Gracilaria Manilaensis and Gracilariopsis Bailinae (Gracilariales, Rhodophyta)." Botanica Marina 39 (2): 123-7.

[19] Freile-Pelegrin, Y., and Robledo, D. 1997. "Influence of Alkali Treatment on Agar from Gracilaria Cornea from Yucatan, Mexico." Journal of Applied Phycology 9 (6): 533-539.

[20] Mollet, J., Rahaoui, A., and Lemoine, Y. 1998. "Yield, Chemical Composition and Gel Strength of Agarocolloids of Gracilaria Gracilis, Gracilariopsis Longissima and the Newly Reported Gracilaria Cf. Vermiculophylla from Roscoff (Brittany, France)." Journal of Applied Phycology 10 (1): 59-66.

[21] Marinho-Soriano, E., Bourret, E., De-Casabianca, M. L., and Maury, L. 1999. "Agar from the Reproductive and Vegetative Stages of Gracilaria Bursa-Pastoris." 
Bioresource Technology 67 (1): 1-5.

[22] Prasad, K., Siddhanta, A. K., Ganesan, M., Ramavat, B. K., Jha, B., and Ghosh, P. K. 2007. "Agars of Gelidiella Acerosa of West and Southeast Coasts of India." Bioresource Technology 98 (10): 1907-15.

[23] Meena, R., Prasad, K., Ganesan, M., and Siddhanta, A. K. 2008. "Superior Quality Agar from Gracilaria Species (Gracilariales, Rhodophyta) Collected from the Gulf of Mannar, India." Journal of Applied Phycology 20 (4): 397-402.

[24] Mehta, G. K., Meena, R., Prasad, K., Ganesan, M., and Siddhanta, A. K. 2010. "Preparation of Galactans from Gracilaria Debilis and Gracilaria Salicornia (Gracilariales, Rhodophyta) of Indian Waters." Journal of Applied Phycology 22 (5): 623-7.

[25] Souza, B. W. S., Cerqueira, M. A., Bourbon, A. I., Pinheiro, A. C., Martins, J. T., and Teixeira, J. A. 2012. "Chemical Characterization and Antioxidant Activity of Sulfated Polysaccharide from the Red Seaweed Gracilaria Birdiae." Food Hydrocolloids 27 (2): 287-92.

[26] Baghel, R., Reddy, C., and Jha, B. 2014. "Characterization of Agarophytic Seaweeds from the Biorefinery Context." Bioresource Technology 159 (May): 280-5.

[27] Pereira-Pacheco, F., Robledo, D., Rodriguez-Carvajal, L., and Freile-Pelegrin, Y. 2007. "Optimization of Native Agar Extraction from Hydropuntia Cornea from Yucatan, Mexico." Bioresource Technology 98 (6): 1278-84.

[28] Sousa, A. M. M., Alves, V. D., Morais, S., Delerue-Matos, C., and Goncalves, M. P. 2010. "Agar Extraction from Integrated Multitrophic Aquacultured Gracilaria Vermiculophylla: Evaluation of a Microwave-Assisted Process using Response Surface Methodology." Bioresource Technology 101 (9): 3258-67.

[29] Armisen, R. 1995. "World-Wide Use and Importance of Gracilaria." Journal of Applied Phycology 7 (3): 231-243.

[30] Melo, M. R. S., Feitosa, J. P. A., Freitas, A. L. P., and De-Paula, R. C. M. 2002. "Isolation and Characterization of Soluble Sulfated Polysaccharide from the Red Seaweed Gracilaria Cornea." Carbohydrate Polymers 49 (4): 491-8.

[31] Freile-Pelegrin, Y. 2005. "Agars from Three Species of Gracilaria (Rhodophyta) from Yucatan Peninsula." Bioresource Technology 96 (3): 295-302.

[32] Siddhanta, A. K., Meena, R., Prasad, K., Ramavat, B. K., Ghosh, P. K., and Eswaran, K. et al. 2005. A Cost Effective Process for Preparing Agarose from Gracilaria Spp. US Patent 20050267296, filed Jun. 1, 2004, and issued Dec. 1, 2005.

[33] Meena, R., Siddhanta, A. K., Prasad, K., Ramavat, B. K.,
Eswaran, K., and Thiruppathi, S. 2007. "Preparation, Characterization and Benchmarking of Agarose from Gracilaria Dura of Indian Waters." Carbohydrate Polymers 69 (1): 179-88.

[34] Ahmad, R., Surif, M., Ramli, N., Yahya, N., Nor, A. R. M., and Bekbayeva, L. 2011. "A Preliminary Study on the Agar Content and Agar Gel Strength of Gracilaria Manilaensis Using Different Agar Extraction Processes." World Applied Sciences Journal 15 (2): 184-8.

[35] Meena, R., Prasad, K., and Siddhanta, A. K. 2011. "Preparation of Superior Quality Products from two Indian Agarophytes." Journal of Applied Phycology 23 (2): 183-9.

[36] Oza, M. D., Mehta, G. K., Kumar, S., Meena, R., and Siddhanta, A. K. 2011. "Galactans from Gracilaria Millardetii and G. Textorii (Gracilariales, Rhodophyta) of Indian Waters." Phycological Research 59 (4): 244-9.

[37] Mouradi-Givernaud, A., Givernaud, T., Morvan, H., and Cosson, J. 1992. "Agar from Gelidium Latifolium (Rhodophyceae, Gelidiales): Biochemical Composition and Seasonal Variations." Botanica Marina 35 (2): 153-9.

[38] Sousa-Pinto, I., Murano, E., Coelho, S., Felga, A., and Pereira, R. 1999. "The Effect of Light on Growth and Agar Content of Gelidium Pulchellum (Gelidiaceae, Rhodophyta) in Culture." Hydrobiologia 398/399 (April): 329-38.

[39] Lahaye, M. 2001. "Developments on Gelling Algal Galactans, Their Structure and Physico-Chemistry." Journal of Applied Phycology 13 (2): 173-84.

[40] Suzuki, H., Sawai, Y., and Takada, M. 2001. "The Effect of Apparent Molecular Weight and Components of Agar on Gel Formation." Food Science and Technology Research 7 (4): 280-284.

[41] Meena, R., Prasad, K., and Siddhanta, A. K. 2006 "Studies on Sugar-Reactivity of Agars Extracted from some Indian Agarophytes." Food Hydrocolloids 20 (8): 1206-15.

[42] Rodríguez, M. C., Matulewicz, M. C., Noseda, M. D., Ducatti, D. R. B., and Leonardi, P. I. 2009. "Agar from Gracilaria Gracilis (Gracilariales, Rhodophyta) of the Patagonic Coast of Argentina-Content, Structure and Physical Properties." Bioresource Technology 100 (3): 1435-41.

[43] Yu, G., Hu, Y., Yang, B., Zhao, X., Wang, P., and Ji, G. et al. 2010. "Extraction, Isolation and Structural Characterization of Polysaccharides from a Red Alga Gloiopeltis Furcata." Journal of Ocean University of China 9 (2): 193-7.

[44] Sousa, A. M. M., Borges, J., Silva, F., Ramos, A. M., Cabrita, E. J., and Gonçalves, M. P. 2013. "Shaping the Molecular Assemblies of Native and Alkali-Modified Agars in Dilute and Concentrated Aqueous Media via 
Microwave-Assisted Extraction.” Soft Matter 9 (11): 3131-9.

[45] Sekkal, M., Huvenne, J., Legrand, P., Sombret, B., Mollet, J., and Mouradigivernaud, A. et al. 1993. "Direct Structural Identification of Polysaccharides from Red Algae by FTIR Microspectrometry I: Localization of Agar in Gracilaria Verrucosa Sections." Microchimica Acta 112 (1-4): 1-10.

[46] Francavilla, M., Pineda, A., Lin, C. S. K., Franchi, M., Trotta, P., and Romero, A. A. et al. 2013. "Natural Porous Agar Materials from Macroalgae." Carbohydrate Polymers 92 (2): 1555-60.

[47] Rees, D. A. 1969. "Structure, Conformation and Mechanisms in the Formation of Polysaccharides and Networks." Advanced Carbohydrate Chemistry and Biochemistry 24 (November): 267-332. doi: 10.1016/S0065-2318(08)60352-2.

[48] Ciancia, M., Noseda, M. D., Matulewicz, M. C., and Cerezo, A. S. 1993. "Alkali-Modification of Carrageenans: Mechanism and Kinetics in the Kappa/iota-, Mu/nu- and Lambda-Series." Carbohydrate Polymers 20 (2): 95-8.

[49] Rebello, J., Ohno, M., Ukeda, H., Kusunose, H., and Sawamura, M. 1997. "3,6 Anhydrogalactose, Sulfate and Methoxyl Contents of Commercial Agarophytes from Different Geographical Origins.” Journal of Applied Phycology 9 (4): 367-70.

[50] Rochas, C., Lahaye, M., and Yaphe, W. 1986. "Sulfate Content of Carrageenan and Agar Determined by Infrared Spectroscopy." Botanica Marina 29 (4): 335-340. doi:10.1515/botm.1986.29.4.335.

[51] Guerrero, P., Etxabide, A., Leceta, I., Peñalba, M., and De-La, Caba, K. 2014. "Extraction of Agar from
Gelidium Sesquipedale (Rhodopyta) and Surface Characterization of Agar Based Films." Carbohydrate Polymers 99 (January): 491-8. doi: 10.1016/j.carbpol.2013.08.049.

[52] Gómez-Ordóñez, E., and Rupérez, P. 2011. "FTIR-ATR Spectroscopy as a Tool for Polysaccharide Identification in Edible Brown and Red Seaweeds." Food Hydrocolloids 25 (6): 1514-20.

[53] Andriamanantoanina, H., Chambat, G., and Rinaudo, M. 2007. "Fractionation of Extracted Madagascan Gracilaria Corticata Polysaccharides: Structure and Properties." Carbohydrate Polymers 68 (1): 77-88.

[54] Li, H., and Zhang, W. 2008. "Optimization and Scale-Up of a New Agar Extraction from Red Seaweed." Journal of Biotechnology $\quad 136 \quad$ (October): $\quad$ S569. doi:10.1016/j.jbiotec.2008.07.1342.

[55] Maciel, J. S., Chaves, L. S., Souza, B. W. S., Teixeira, D. I. A., Freitas, A. L. P., and Feitosa, J. P. A. et al. 2008. "Structural Characterization of Cold Extracted Fraction of Soluble Sulfated Polysaccharide from Red Seaweed Gracilaria Birdiae." Carbohydrate Polymers 71 (4): 559-65.

[56] Moderate Resolution Imaging Spectroradiometer. 2013. "Sea-Surface Temperature Measurements (MODIS) on Aqua and Terra." Monthly Average Sea Surface Temperature (April-May 2013). Accessed May 20, 2015. http://modis.gsfc.nasa.gov/.

[57] Truus, K., Tuvikene, R., Vaher, M., Kailas, T., Toomik, P., and Pehk, T. 2006. "Structural and Compositional Characteristics of Gelling Galactan from the Red Alga Ahnfeltia Tobuchiensis (Ahnfeltiales, the Sea of Japan)." Carbohydrate Polymers 63 (1): 130-5. doi:10.1016/j.carbpol.2005.08.029. 